\title{
Outcrop-scale tomography: insights into the 3D structure of multiphase boudins
}

\author{
Christoph von Hagke ${ }^{1}$, Bob Bamberg ${ }^{1}$, Simon Virgo ${ }^{1}$, Janos L. Urai ${ }^{1}$ \\ Institute of Structural Geology, Tectonics and Geomechanics, RWTH Aachen University, \\ Lochnerstrasse 4-20, D-52056 Aachen, Germany, www.ged.rwth-aachen.de
}

\begin{abstract}
We analyze the 3D geomorphology of a boudinaged amphibolite layer encased in marble using meter-scale tomography by serial sectioning, high resolution imaging and $3 \mathrm{D}$ reconstruction of a $2 \mathrm{~m}^{3}$ block from a quarry in the high-grade core of the Naxos core complex. Local uncertainties in the model are resolved by dissolution of marble in selected slabs, yielding a large, highly accurate 3D model.

Results show five generations of brittle extension of the amphibolite in ductile marble, although examination of the boudinaged layer on the outside of the block only suggested one generation. Most prominent are the rotated domino boudins, where part of the dilatancy between domino boudins can be shown to be due to later reactivation. Shear fractures between domino boudins have relatively large throw gradients, indicating ductile rupture. Layer-parallel stretch as measured by reconstruction of domino boudins decreases with amphibolite layer thickness although the layer has undergone the same bulk stretch everywhere. This suggests that with decreasing layer thickness deformation becomes delocalized, offering tantalizing glimpses of rheology under metamorphic conditions.
\end{abstract}




\section{Introduction}

Periodic structures in layered rocks have long been recognized as powerful proxies to mechanical properties, kinematics and rheology during deformation (e.g. Kenis et al., 2005; Ramberg, 1955). Whereas research largely focused on structures formed by layer-parallel shortening (folds and mullions) (Adamuszek et al., 2013; Ghassemi et al., 2010; Grasemann and Schmalholz, 2012; Grasemann and Stüwe, 2001; Hudleston and Treagus, 2010; Kaus and Schmalholz, 2006; Kenis et al., 2004; Kenis et al., 2005; Llorens et al., 2013; Ruh et al., 2012; Schmalholz and Podladchikov, 1999; Schmalholz and Schmid, 2012; Schmid and Podladchikov, 2006; Schrank et al., 2008), boudins, which are their extensional counterparts, have not received similar attention, despite their ubiquity and possibly greater potential as structural and rheological proxies: boudins form by a large spectrum of deformation mechanisms, reaching from brittle fracture over ductile rupture to ductile localization (e.g. Gardner et al., 2015; Goscombe and Passchier, 2003; Maeder et al., 2009; Schmalholz and Maeder, 2012; Van Noten and Sintubin, 2010; Zulauf and Zulauf, 2005).

Boudins contain first order information about the bulk strain and vorticity. The rotation of boudin blocks is often used to infer the bulk shear sense and vorticity (Dabrowski and Grasemann, 2014; Goldstein, 1988; Goscombe and Passchier, 2003; Hanmer, 1986). Further information on fluid pressures and p-T conditions during deformation may be preserved in the surrounding matrix as well as structurally controlled secondary mineralization in the necks of the boudins (e.g. Schenk et al., 2007). Boudins occur in a wide range of tectonic settings and at all scales (Goscombe et al., 2004; Gueguen et al., 1997; Jolivet et al., 2009; Reuning et al., 2009; Schoenherr et al., 2009; Strozyk et al., 2014). Boudins can be diagnostic for polyphase deformation, since polyaxial stretching results in a different 3D structure than polyphase deformation in different directions (Abe et al., 2013; Ghosh, 1988; Reber et al., 2010; Zulauf et al., 2014). This diversity makes boudins ideal structures to understand better and quantify rock deformation in the brittle and ductile regime.

From field data boudinage with different failure modes have been recognized, ranging from brittle extension fracturing to ductile pinch-and-swell, and a taxonomy has been established based on description of the boudin shapes, orientation of the boudin train, as well as presence or absence of mineralization between the individual boudins (Goscombe et al., 2004). Much of the current classification is based on 2D observation. However, boudinage is a complex phenomenon that involves different deformation mechanisms and has complex shapes in 3D (e.g. Abe et al., 2010; Goscombe et al., 2004; Passchier, 2001; Weiss, 1972; Zulauf and Zulauf, 2005; Zulauf et al., 2014; Zulauf et al., 2011). Using numerical models, the different failure modes observed in the field could be reproduced, (e.g. Bai and Pollard, 2000; Schmalholz et al., 2008; Schöpfer et al., 2011), analogue and numerical models of boudinage show that boudins can evolve simultaneously with folding, and boudin geometries depend on the type of strain in 3D (Abe et al., 2013; Kobberger and Zulauf, 1995). Whereas analogue models may be conducted without initial fractures and show how brittle and ductile processes are important in boudinage (e.g. Zulauf et al., 2003; Zulauf et al., 2014), numerical models commonly prescribe initial fractures in the competent layer, thus introducing boundary conditions e.g. on boudin lengthwidth ratio, and rendering multi-stage boudinage models challenging. Only few studies successfully show the complete dynamic evolution of boudins from initial loading to layer necking in the ductile regime (Schmalholz et al., 2008), or layer rupture and boudin formation for discontinuous structures (Abe and Urai, 2012; Komoróczi et al., 2013). Despite these efforts, we have limited understanding of fluid flow and vein growth in the boudin necks, and how boudins form at the brittle-ductile transition is a poorly understood process. Furthermore, it has been shown that without 3D information structures may be wrongly interpreted as boudinage (apparent boudinage c.f. Bons et al., 2004).

One cause for our incomplete knowledge is the lack of high-resolution 3D data of boudins, in single or in multiple deformation phases. Whereas boudins at millimeter or centimeter-scale may be imaged using medical and $\mu$-computer tomography (Zulauf et al., 2009) 3D geometry of boudins is usually not easily obtained as most field exposures of boudins only provide $2 \mathrm{D}$ sections.

A spectacular site where amphibolite and pegmatite boudins at centimeter to decimeter scale are exposed, is the marble quarries on Naxos, Greece (Schenk et al., 2007; Virgo et al., 2018), Fig. 1A. Located in the center 
of the Aegean Sea, Naxos has undergone a complex deformation history associated with long-lived roll-back of the Hellenic subduction zone (e.g. Gautier et al., 1993). It is a classic metamorphic core complex and due to its central location and exposure of the North Cycladic Detachment system is has been identified as prime target for understanding the regional geology of the eastern Mediterranean, but also for investigating evolution of rheology under changing metamorphic grades (e.g. Jolivet et al., 2009; Urai et al., 1990). The island has undergone at least three metamorphic phases, ranging from early high-pressure-low-temperature to greenschist facies and localized high-temperature-low pressure metamorphism including partial anatexis (Urai et al., 1990). These events associated with N-S stretching and E-W-shortening resulted in coaxially refolded folds and boudinage structures within the marbles and the intercalated amphibolite and pegmatite layers (Schenk et al., 2007; Virgo et al., 2018). Two generations of pinch-and-swell boudins stretch the amphibolite layer by $\gg 100 \%$, followed by pegmatite intrusion and several brittle boudinage phases (Virgo et al., 2018).

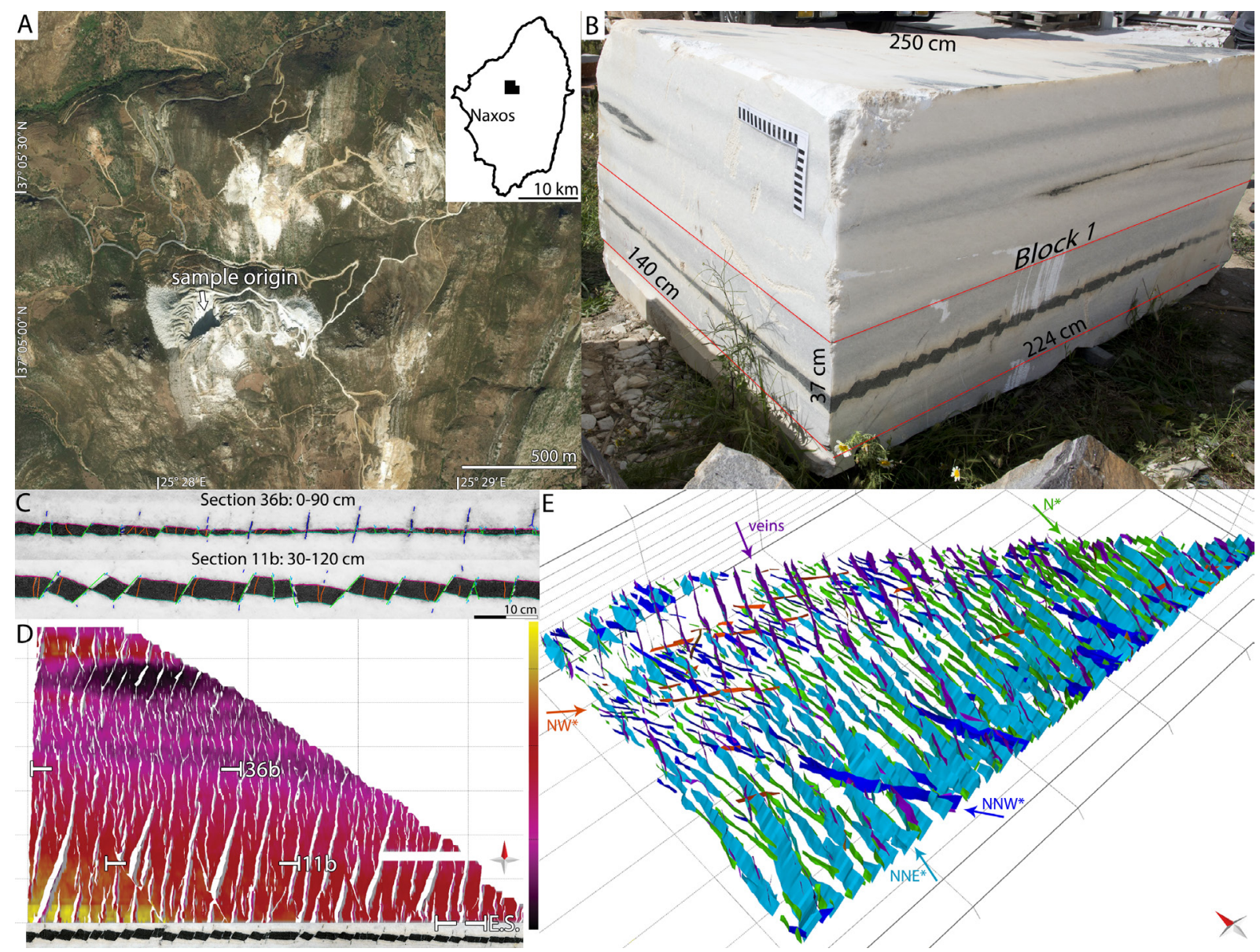

Figure 1: A: Location of the quarry on Naxos, central Aegean. B: Marble block with boudinaged amphibolite layer. On the faces, the block shows drawn boudins on one side and domino boudins on the other. Red lines indicate later cutting. C: Two exemplary section interpretations of multiphase boudinage in the same amphibolite layer. See (D) for location within the block. A more complete series of slices in provided in the supplement. D: Thickness map of the amphibolite layer. Drawn boudinage striking E-W causes thickness variation between $50.5 \mathrm{~mm}$ (yellow) to o $\mathrm{mm}$ (black). Domino boudins only occur in thicker amphibolite and gradually disappear as the amphibolite pinches out. Grid spacing is $20 \times 50 \mathrm{~cm}$. E: $3 D$ visualization of mapped fractures. Fracture mapping allows for establishing cross-cutting relationships and relative ages. Generations are from young to old: (1) Cyan: chlorite filled fractures (veins) (2) Green: torn boudins with apertures of o-3 mm (3) Light blue: domino boudins (4) Dark blue: domino-torn boudins (5) Orange: torn boudins without discernible aperture. Horizontal grid spacing is $20 \times 50 \mathrm{~cm}$. A video of the rotating block is provided in the digital supplement.

Schenk et al. (2007) and (Virgo et al. 2018) provide detailed documentation of the pegmatite and amphibolite boudins, respectively, including multiple outcrop and thin section pictures. The site provides $3 \mathrm{D}$ outcrop that has undergone at least five different generations of boudinage under different P-T-conditions, ranging from ductile to brittle deformation (Virgo et al., 2018). Field and thin section analyses show that the amphibolite has undergone two ductile deformation phases, resulting in pinch-and-swell boudins and isoclinal 
folds, followed by four brittle boudinage phases, which are oriented at high angle to the ductile structures (Virgo et al., 2018).

However, even with the exceptional outcrop conditions, many critical details of these structures remain elusive, and traditional methods of tomography (e.g. seismic wave, ultrasound, X-ray, Ion Beam) cannot access the several $\mathrm{m}^{3}$ volumes in which this information is hosted. Therefore, we developed an "outcrop-scale tomography" procedure of selecting a number of critical blocks from the quarry, serial sectioning it using industrial equipment followed by 3D reconstruction. Although initially used exclusively for non-destructive analysis using waves, essentially tomography is reconstructing a volume from multiple slices. This approach allows for determining boudin geometries and boudin train morphology in $3 \mathrm{D}$, mapping crosscutting relationships, analysis of the structures within the surrounding marble, and micro-structural analysis everywhere in the volume.

In this paper, we present a detailed analysis of the 3D geometry of a multiply boudinaged amphibolite layer at the meter scale. We analyze brittle boudins formed at high angle to the pinch and the swell in an older boudin to investigate how layer thickness controls boudinage geometry. Our goal is to show how rich a structural and rheological archive boudins are when studied at this scale, and how incomplete or even misleading 2D observations may be. 3D outcrop scale tomography is an exciting prospect, with the potential for fundamental progress in our understanding of boudinage dynamics in particular, and rock rheology in general.

\section{Methods}

For detailed analysis of the 3D geometries we selected a marble block mined from the quarry containing a single straight amphibolite layer. The block is wedge-shaped, $36 \mathrm{~cm}$ high, and the three faces are 140, 224, and $250 \mathrm{~cm}$ long Fig. 1B). On one side of the block the amphibolite layer shows domino boudins, separated by shear and extension fractures (Fig. 1B). On the other side it shows meter scale gradual change in thickness, in an earlier pinch-and swell boudin. We purchased this block from the mine, transported it into the marble workshop (see figure in digital supplement), and after carefully measuring and marking it, cut the block into $\mathrm{cm}$-thick slices perpendicular to the necks of the well-expressed domino boudin generation. The average thickness of the slabs is $2 \mathrm{~cm}$ and kerf loss is $1 \mathrm{~cm}$. We took 36MP pictures of the slices using a Nikon D80o camera with a Nikkor Micro $60 \mathrm{~mm} \mathrm{f/2.8D} \mathrm{lens.} \mathrm{This} \mathrm{yields} \mathrm{a} \mathrm{resolution} \mathrm{of} 0.2 \mathrm{~mm}$ per pixel and a negligible distortion of $1 \mathrm{~mm}$ over a frame width of $1450 \mathrm{~mm}$. Reconstructing a 3D model from the slabs used the same workflow as interpreting a $3 \mathrm{D}$ seismic survey. Photographs of the slabs were spatially referenced and loaded as sections into Midland Valley's Move 2016 suite (www.mve.com). Using these images, fractures were traced, correlated and classified according to their failure mode, layer boundaries were mapped, and inter-boudin zones were traced to measure dilatancy between boudins (Fig. 1D and E). The in situ orientation and origin of the marble block in the quarry can be reconstructed, and the results can be compared with the results of Virgo et al. (2018) (see below). However, in this paper we use a reference frame defined by the sides of the block where the face of the longest slab is vertical and strikes $\mathrm{E}-\mathrm{W}^{*}$ (directions in this reference frame are indicated with an asterisk). In total, 5087 fracture traces were mapped. After digitizing each section, traces are interpolated across sections, creating a 3D network of a total of 841 fracture planes. With this approach, we determine boudin thickness (i.e. distance between top and bottom surface at each vertex), fracture orientation, length, dilatancy, throw, heave, and spacing. To corroborate the 3D interpolation in selected locations where the slab thickness allowed aliasing, we etched away the marble with hydrochloric acid for selected slabs, fully exposing the amphibolite boudins. 


\section{Results}

Multiple boudinage sets exist within the amphibolite layer, corroborating findings of Virgo et al. (2018). The entire layer shows thickness variations due to pinch-and-swell structures (Fig. 1). We identified five brittle boudinage sets overprinting the ductile structures (Fig. 1, Table 1). Based on orientation and failure mode these are

1. straight continuous torn boudins with sub-millimeter aperture (orange in Fig. 1). They strike NW* $\left(122^{\circ *} \pm 9.2^{\circ}\right.$, orange), respectively. Owing to their small aperture, they are only sparsely identified and mapped in the $3 \mathrm{D}$ models. In the etched samples (see below), they are more easy to identify (Fig. 2).

2. boudins striking $\mathrm{NNW}^{*}\left(157^{\circ *} \pm 14.2^{\circ}\right.$ dark blue in Fig. $\left.1 \mathrm{E}\right)$. Many of the fractures only have an extensional component, but shear fracturing is common, particularly where the amphibolite is thicker. Because this set features both domino and torn boudins we term it "domino-torn boudins". Inter-boudin zones dip $247 / 83^{\circ *}$ on average, but can dip as shallow as $55^{\circ *}$. Where observable, throw ranges from 1.8 to $4.5 \mathrm{~mm}$ with an average of $0.5 \mathrm{~mm}$. In rare cases throw of $>10 \mathrm{~mm}$ occurs in thick amphibolite.

3. domino boudins striking $\mathrm{NNE}^{*}\left(5^{\circ *} \pm 15 . \mathrm{O}^{\circ}\right)$ (light blue in Fig. 1E). Inter-boudin zones dip $275 / 60^{\circ *}$ on average and throws range from 1.2 to $30 \mathrm{~mm}$ with an average of $8.3 \mathrm{~mm}$. In thin amphibolite, few fractures are present, but generally domino boudins are more abundant in amphibolite thicker than $\sim 10$ $\mathrm{mm}$. Mostly, they have a dilatational component of up to $3 \mathrm{~mm}$ extension. These boudins show hybrid fractures, as indicated by chlorite mineralization with slickenfibers in the inter-boudin zones.

4. torn boudins striking $\mathrm{N}^{*}\left(178 \pm 15^{\circ *}\right)$ with apertures of $<3 \mathrm{~mm}$ (green in Fig. 1). They are the most abundant fractures in the block.

5. chlorite filled fractures (veins), striking $\mathrm{NNE}^{*}\left(18^{\circ *} \pm 14.0^{\circ}\right)$ and protruding into the marble (purple in Fig. 1E). Their length normal to the amphibolite layer remains constant at 4 to $5 \mathrm{~cm}$ and spacing is independent of layer thickness, ranging between 5 and $10 \mathrm{~cm}$.

Table 1: A: Brittle deformation generations summarized with their characteristics and relative interference structures. The number of chlorite veins is so high because fragments of the same vein separated by calcite (see panel B) are counted separately. B: Typical interboudin fractures for each set. Purely extensional fractures of the $N N W^{\star}$ set are similar to $N^{\star}$ fractures. The scale is identical for all pictures.

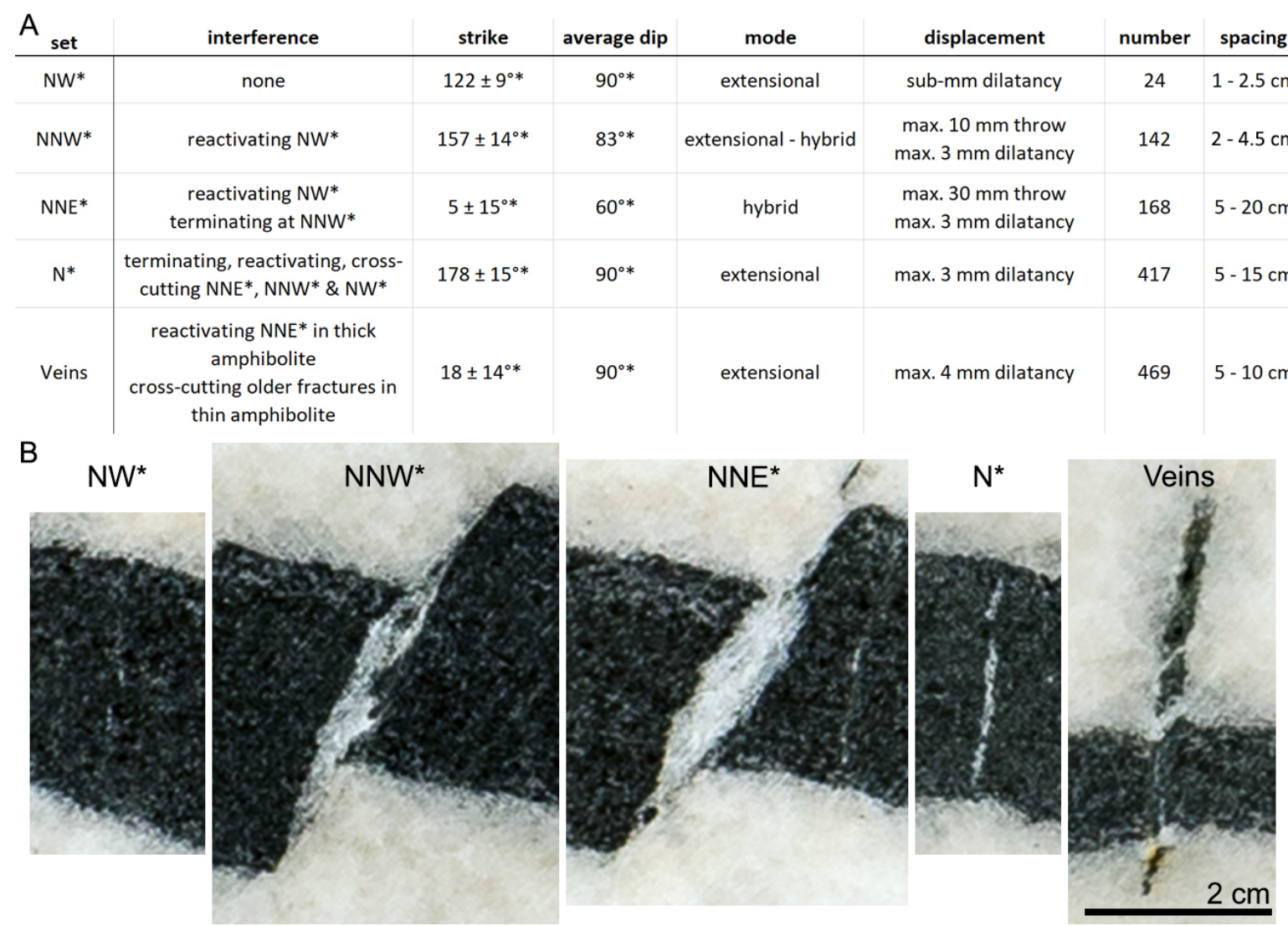


Using these results, it is possible to orient the marble block within the quarry by comparing the different boudinage sets with results of Virgo et al. (2018). The chlorite filled fractures strike NNE* in the block, and dip at $60^{\circ}$ to the north in outcrop. This allows for only two possible original orientations of the block with subvertical $\mathrm{N}^{*}$ or $\mathrm{S}^{*}$.

The close spacing of the sections (one or two $\mathrm{cm}$ ) ensures that interpolation of fracture sets between sections is only subject to minimal aliasing errors, making the model robust. An important observation is the NNE* and $\mathrm{NNW}^{*}$ shear planes which are not discernible in section view, only three-dimensional analysis allows for their differentiation. Furthermore, in 3D it becomes apparent that shear fractures are much less prominent in areas of thin amphibolite, and absent where the amphibolite is thinner than $\sim 10$ millimeters (Fig. 1E). Correlations of fractures between adjacent $2 \mathrm{D}$ sections were tested by dissolving the marble surrounding the amphibolite in hydrochloric acid (Fig. 2). All five brittle fracture sets interpreted in the 3D model can be identified in the etched samples. Using the combination of the $3 \mathrm{D}$ observations from the model and etched blocks it is possible to determine overprinting relationships of different sets (Table 1). For instance, chlorite filled veins are commonly observed striking through tips of neighboring domino boudins, indicating they are younger; $\mathrm{N}^{*}$ striking torn boudins terminate at, reactivate, or crosscut domino boudins. Crosscutting relationships allow for establishing a relative chronology of the structural sets. These are from old to young (1) straight, continuous torn boudins $\left(\mathrm{NW}^{*}\right),(2)$ domino-torn boudins ( $\left.\mathrm{NNW}^{*}\right),(3)$ domino boudins $\left(\mathrm{NNE}^{*}\right)$, (4) torn boudins $\left(\mathrm{N}^{*}\right)$, and (5) chlorite filled fractures $\left(\mathrm{NNE}^{*}\right)$. Two key observations could be made only by inspecting $3 \mathrm{D}$ geometries of fracture surfaces. First, boudins that in 2D apparently belong to the same set are in fact the result of two different sets (Fig. 3A). This is exciting, as it implies a straightforward interpretation of boudin length-width ratio is in this case not possible. Second, the dip direction of a fracture may change along strike (Fig. 3 B,C). This implies that at least locally it is not possible to interpret fracture dip as shear sense indicator, corroborating findings of Schöpfer et al. (2017).

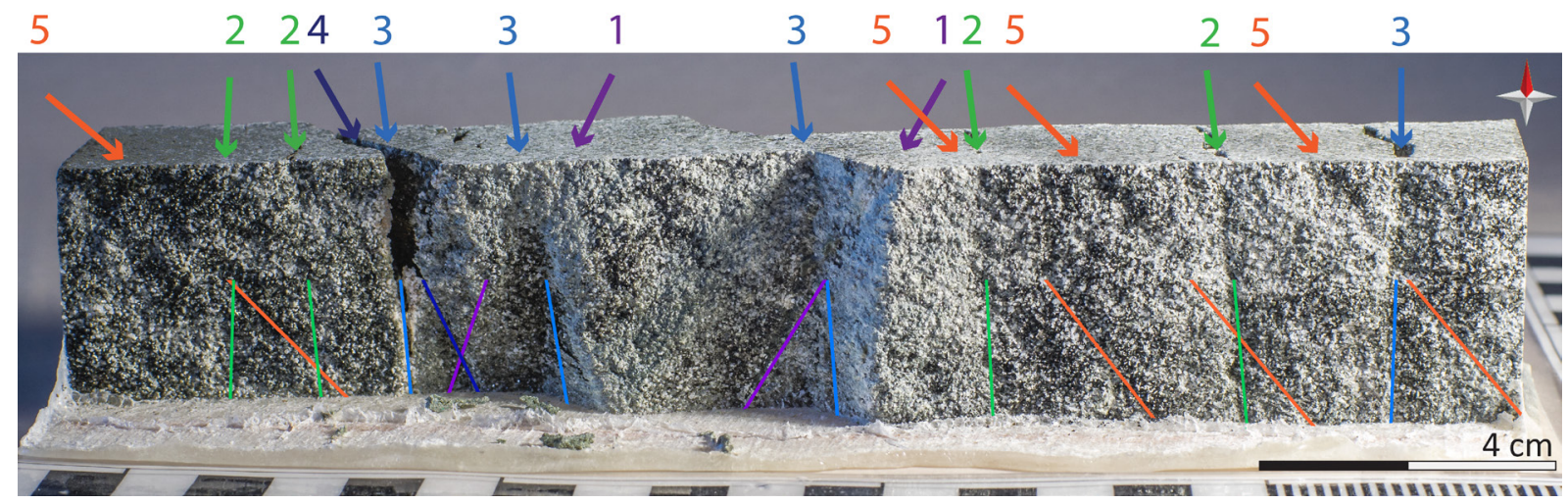

Figure 2: Map view of fractures in a $19 \mathrm{~cm}$ long amphibolite sample from slab 1, isolated by dissolving the marble matrix in hydrochloric acid. Numbers refer to different boudin sets sorted from oldest to youngest, arrows indicate fracture orientation. Colors as in Fig. $1 E$. Cross cutting relationships corroborate age relations as seen in the entire block (Fig. 1E). A 3D pdf of the etched sample (72 MB) is available on request.

In addition to crosscutting relationships and fracture orientation, high-resolution 3D analysis reveals the geometry of younger sets is partly influenced by older sets, and sometimes older generations are reactivated. Interaction of different sets result in complex inter-boudin zones and boudin geometries observed in the $2 \mathrm{D}$ sections. For instance, intersecting shear or extensional fractures with high (few $\mathrm{mm}$ ) aperture produce narrowing slivers or wedges with often cuspate-lobate outer surfaces. As a result of torn boudins crosscutting and reactivating domino boudins, displacement can vary considerably between neighboring domino boudins of the same set. A compilation of pictures showing these intersecting structures is provided in the supplement. Other examples including microstructures can be found in Virgo et al. (2018). 


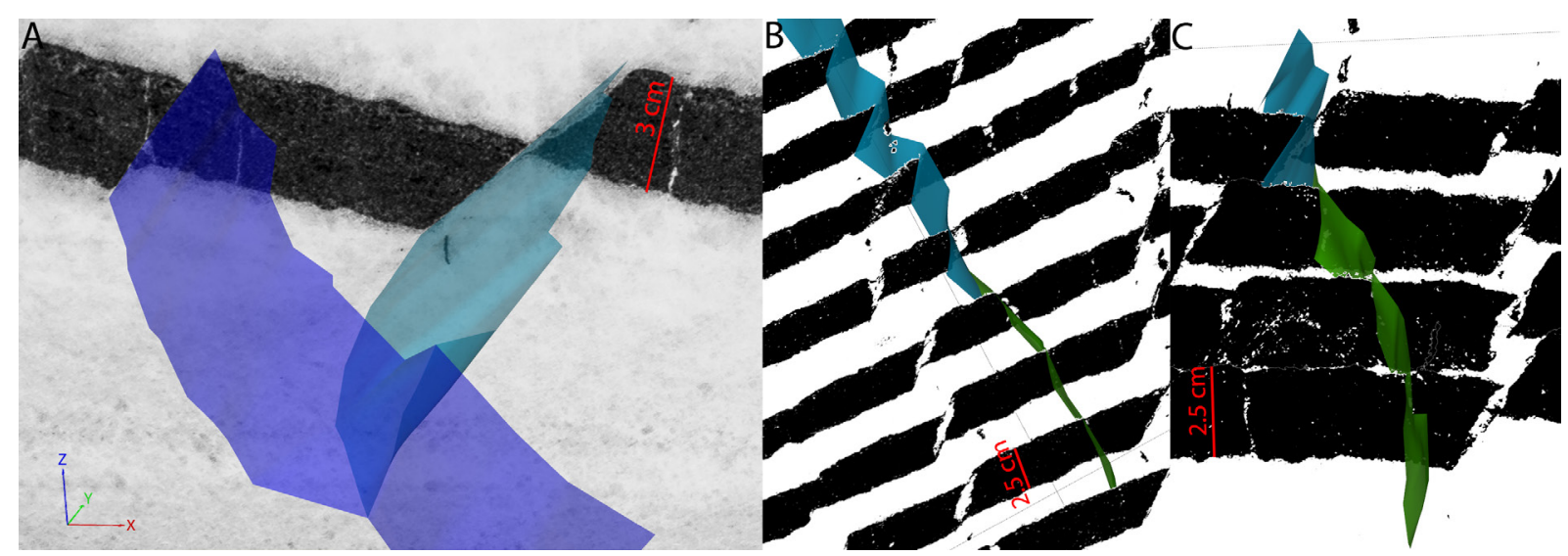

Figure 3: $2 D$ vs $3 D$ ambiguity and $3 D$ switch. A: Different generations with same deformation mode are only discernible in $3 D$. $B$ \& C: Failure mode may change along fractures, $2 D$ observation will thus lead to potentially misleading classification and stress/strain field reconstruction.

Fractures splay or abruptly change their direction or failure mode when intersecting older fracture generations (Virgo et al., 2013; Virgo et al., 2014). A typical expression are disrupted chlorite slickenfibres between $\mathrm{NNE}^{*}$ boudins. Another example for reactivation is increased aperture of $\mathrm{NW}^{*}$ fractures where they are cut by the torn boudins $\left(\mathrm{N}^{*}\right)$. The interference mechanism between the two sets can be described as internal deflection (cf. Virgo et al., 2013), where fractures propagate in the amphibolite and reactivate parts of older fractures when joining them. Extensional fractures, usually with sub-mm aperture, are frequently concentrated in the tips of domino boudins. In 3D, they run parallel to the shear plane over several sections, without significant variation in their dimension or displacement. However, macroscopically, it is difficult to distinguish whether dilatancy occurred in several phases or are the result of a single reactivation event. $\mathrm{N}^{*}$ fractures regularly extend the tips of $\mathrm{NNE}^{*}$ and $\mathrm{NNW}^{*}$ fractures, which is visible in a sudden switch of orientation and failure mode. These interactions may at least partly be responsible for the highly variable fracture spacing observed in the different sets (Table 1). Indeed, only the youngest generation, the chlorite filled fractures, show regular spacing of 5-10 cm, independent of layer thickness.

Extension localized in brittle boudinage is either accommodated by purely layer parallel dilatancy or by heave, the layer parallel component of shear slip (Fig. 4). The etched blocks expose the shear planes between domino boudins. They consistently display pronounced striations through chlorite slickenfibres, indicating the movement between the boudin blocks was pure dip-slip. Extension is measured in 27 sections at $4^{\circ}$ obliquity to the axis of the drawn boudins. Dilatancy is mapped in the sections and the traces are interpolated to generate a map of dilatant inter-boudin zones. Predominantly inter-boudin zones striking $\mathrm{NNE}^{*}, \mathrm{~N}^{*}$, and chlorite filled fractures are dilatant, but also $\mathrm{NNW}^{*}$ trending fractures show dilatancy. To quantify extension, inter-boudin zone width measured in the $\mathrm{E}-\mathrm{W}^{*}$ striking sections has to be corrected taking into account that fracture and section are not perpendicular (i.e. we measure apparent widths). Depending on the angle between fracture and section, measured values in $\mathrm{NNE}^{*}, \mathrm{~N}^{*}$, and $\mathrm{NNW}^{*}$ sections have to be multiplied by values ranging between 0.995 and 0.999 , showing the relatively small difference between apparent and actual extension. Values of dilatancy and heave are normalized by amphibolite length in the section, for which we sum up the lengths of the upper surfaces of every boudin, thus accounting for boudin rotation. resulting values provide a direct approximation of finite strain from brittle deformation (and accounts for the different lengths of the analyzed rock slabs).

Dilatancy ranges between 4 and $7 \%$ (Fig. 4). No correlation with layer thickness is observable. Dilatancy in amphibolites with thicknesses below $\sim 10 \mathrm{~mm}$ is limited to the chlorite filled fractures. However, a surprising observation is that heave positively correlates with layer thickness, increasing from o extension below $10 \mathrm{~mm}$ thickness to $12 \%$ at $30 \mathrm{~mm}$ thickness (Fig. 4). As dilatancy is constant but heave increase with thickness, the ratio of dilatancy / heave decreases with thickness. This implies for thickness values of less than $\sim 25 \mathrm{~mm}$, dilatancy dominates measurable extension, whereas for thicknesses $>25 \mathrm{~mm}$, heave dominates. In total, this results in a linear or exponential relationship between measurable brittle extension and layer thickness, both of which fit the data equally well $\left(\mathrm{R}^{2}=0.98\right.$; Fig. 4$)$. When layer thickness is less than the grain size of the 
surrounding marble, no boudinage of any style is observed. This effect is also seen in the pegmatite showing blocky boudins of Schenk et al. (2007), where a thin amphibolite layer next to the boudinaged pegmatite shows no boudinage but must have the same bulk stretch as the pegmatite.

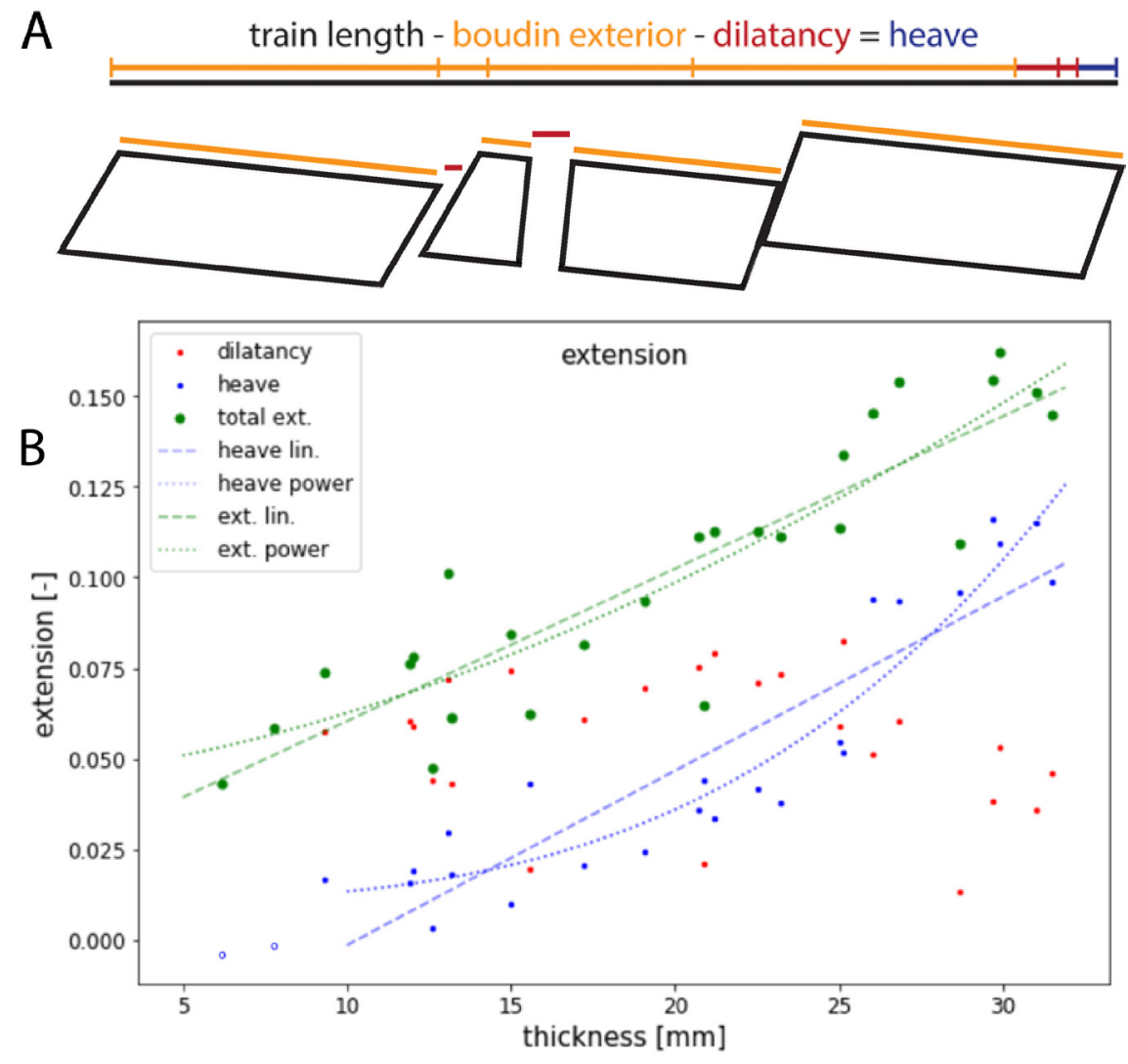

Figure 4: A: Extension measurement: Total extension is the difference between the boudin train length and the outer surface of the amphibolite boudins. Heave is calculated as the difference between total extension and the dilatancy traces. B: Correlation between visible extension and thickness for brittle boudinage. Extension is recorded as dilatancy (red) or heave (blue). While heave is positively correlated with thickness, dilatancy is largely independent. This implies for thick layers heave dominates extension, but for thin layers dilatancy is more dominant. Negative heave values (open circles) are likely the result of distributed extension within the amphibolite layer. Total visible extension (dilatancy + heave) also depends on thickness and varies between $5 \%$ at $5 \mathrm{~mm}$ thickness and $16 \%$ at $32 \mathrm{~mm}$ thickness.

\section{Discussion and Conclusions}

The existence of multiple fracture sets within the block is surprising, as even though boudins are well exposed along a saw cut surface, no conclusive indications for multiple fracture sets are present in $2 \mathrm{D}$ sections. The inferred chronology for boudinage is in line with findings of Virgo et al. (2018), who show all sets form during E-W shortening, whereas the extension direction evolves from vertical to south vergent, horizontal and eventually north vergent. However, field data did not allow for distinguishing the $\mathrm{NNW}^{*}$ and NNE* striking boudins as separate sets, despite exceptional outcrop conditions. This may be because of the similar orientation of some fracture sets, but also due to reactivation features. The frequent reactivation is expected for the observed small angels between the boudin sets. DEM models of multiphase fracture propagation show that strength ratio between host rock (here the amphibolite layer) and fracture infill (corresponding to host rock in the inter-boudin zones, i.e. marble) are the primary controls on the type of vein interaction (Virgo et al. 2014, 2016a). For the small angles between $\mathrm{NNE}^{*}, \mathrm{~N}^{*}$, and $\mathrm{NNW}^{*}$ sets an almost complete reactivation of older fractures with few antithetic new fractures is expected for high strength ratios (Virgo et al., 2016a). Such reactivation can be observed for veins in thick amphibolite, implying that the strength contrast between amphibolite and marble in the inter-boudin zones was high during the last deformation generation. Interactions of $\mathrm{N}^{*}$ fractures with domino boudins are however characterized by deflection, implying a much lower strength contrast between both lithologies during this deformation phase. 
A major finding of the 3D analysis is that stretch indicated by shear offset on blocky boudins decreases with amphibolite layer thickness. When layers are thinner than $\sim 10$ millimeters, only limited macroscopic shear fractures are visible, despite layer parallel extension. For torn boudins no correlation between thickness and dilatancy is apparent. However, dilatancy in the amphibolite layer includes strain from extensional fracturing and the pure extensional component of hybrid fractures. It originates from a superposition of apertures of the veins, $\mathrm{N}^{*}$ striking torn boudins and the extensional component of $\mathrm{NNE}^{*}$ striking hybrid shear fractures. This reactivation may at least partly be responsible for the high variability of dilatancy measurements (Fig. 4). These two observations are important for our understanding of interpreting boudinage structures in 2D. Firstly, the amount of strain determined from domino boudinage may be underestimated, and secondly, 2D interpretation of stretch within one boudin set may be misleading, as large amounts of dilatancy may be associated with reactivation features that formed in a different stress field.

Results of this study may be compared with results of Schenk et al. (2007), who studied a boudinaged pegmatite from the same outcrop. The pegmatite intruded after the early pinch-and-swell boudins were formed, so it has only undergone the brittle deformation phases together with the amphibolite. However, the pegmatite shows only domino boudinage (and not the other brittle phases), even though the rocks have undergone the same overall strain. This indicates either the amphibolite had a more brittle rheology than the pegmatite as it formed torn boudins, or that in those parts of the marble where the pegmatites are present strains in the brittle phases are slightly different. Here we note that in the interpretations of Schenk et al. (2007), the domino boudins formed under conditions where there was extensive dynamic recrystallization of the marble and used the dynamically recrystallized grainsize to estimate the shear stress in the marble. However, Virgo et al., (2018) have shown that the domino boudins formed after the recrystallization of the marble. This will be addressed in detail in a follow-up study.

Interestingly, amphibolite and pegmatite show similar displacement gradients (Fig. 5). However, to fully test this, additional measurements would have to be taken in the pegmatite and amphibolite, preferentially from multiple sites within the quarry.

A major finding of the $3 \mathrm{D}$ analysis is that the layer-parallel stretch indicated by shear offset on blocky boudins decreases with amphibolite layer thickness. When layers are thinner than 10 millimeters, macroscopic shear fractures disappear. One reason for this could be that the thinner layers were stretched less. However, considering that the thin part of the amphibolite layer is flanked on both sides by a thicker layer, this hypothesis is rejected, and we conclude instead that the thin parts of the layer underwent the same stretch, but deformed without localizing strain, in a macroscopically ductile fashion.

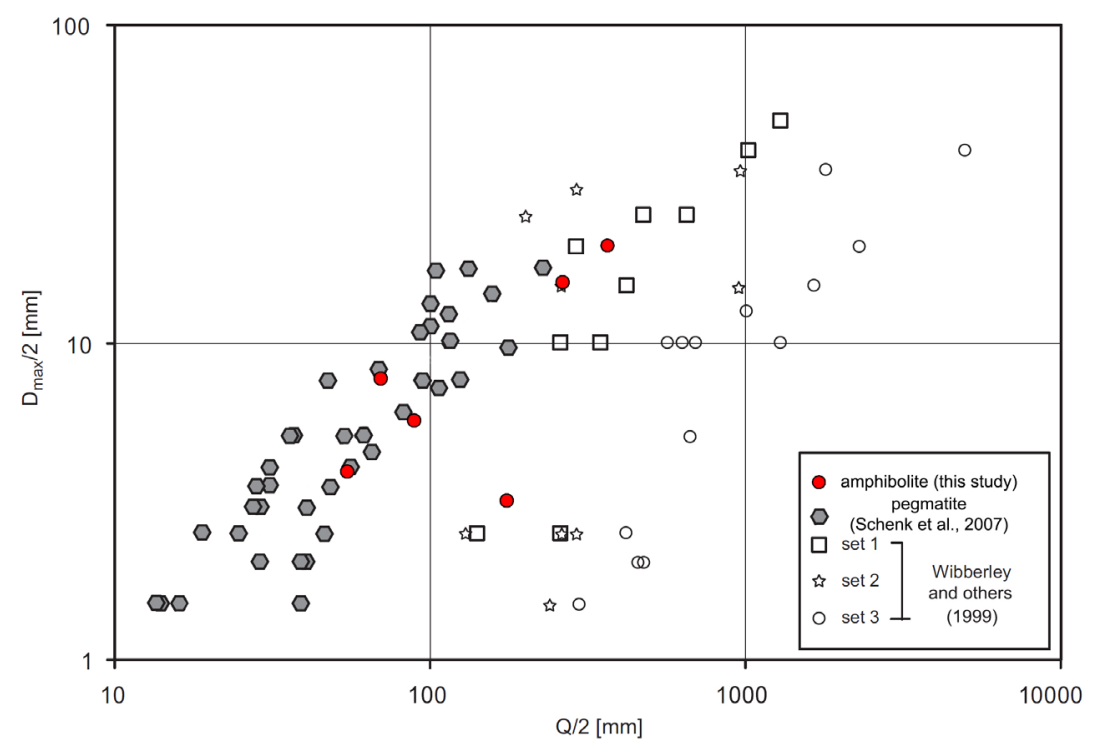

Figure 5: Displacement gradients of the amphibolite boudins analyzed in this study as compared to pegmatite within the same outcrop (Schenk et al. 2007), and with faults in unconsolidated sand, Morocco (Wibberley et al., 1999). Modified after Schenk et al. (2007). 
For the torn boudins on the other hand, no correlation between thickness and dilatancy is apparent, keeping in mind that dilatancy in the amphibolite layer includes strain from extensional fracturing and the extensional component of hybrid fractures. It originates from a superposition of apertures of the veins of $\mathrm{N}^{*}$ striking torn boudins and the extensional component of NNE* striking hybrid shear fractures. This superposition is interpreted to be responsible for the variability of dilatancy measurements (Fig. 4).

These two observations are important for interpreting boudinage structures in $2 \mathrm{D}$ outcrops. Firstly, the amount of strain determined from domino boudinage may be underestimated, and secondly, 2D interpretation of stretch within one boudin set may be misleading, as large amounts of dilatancy may be associated with reactivation features that formed in a different stress field.

The findings of this study highlight the importance of a three-dimensional data for the analysis of boudinage. Only knowledge about the geometrical changes in the third dimension provided the data necessary to differentiate between different boudin sets with the same failure mode or to establish age relationships between different boudin sets. Both $\mathrm{NNE}^{*}$ and $\mathrm{NNW}^{*}$ boudins manifest as nearly identical domino boudins in sections, but are easily distinguishable through their strike direction within the layer. The similarity between different sets in sections is even more pronounced for torn boudins (cf. $\mathrm{N}^{*}$ and $\mathrm{NNW}^{*}$ fractures in thin amphibolite). 3D mapping allows for linking boudins with a dominant shear component with torn boudins (Fig. 3). From only looking at the 2D section, the same set would probably have been interpreted as expression mechanical heterogeneity. Establishing age relations between different boudin sets is virtually impossible in 2D when the shortening directions remained similar (e.g. between $\mathrm{NNE}^{*}$ and $\mathrm{N}^{*}$ fractures), unless one interboudin fracture clearly disrupts another. Likewise, reconstruction of the principal strain axes requires knowledge of the exact three-dimensional orientation of the boudin structures. The development of boudin separating fractures as relays planes additionally emphasizes the importance of a three-dimensional characterization. Observations made in one section plane cannot be extrapolated in the third dimension, neither do they represent the actual stress state within the layer. In most of the published studies where 3D boudins are sufficiently documented, there is evidence for more than one phase of deformation. Therefore, perhaps a bit provocatively, we propose that the 2D-based taxonomy needs careful reevaluation.

\section{Acknowledgements}

This work was funded by the Deutsche Forschungsgemeinschaft (DFG) in project "BoDy - Boudinage Dynamics" (UR 64/14-1). We thank the owners of the quarries around Kinidaros (Karpontini Bros - Naxian Marbles - karpontinibros.gr/ and Naxos Marble S.A. - naxos-marble.com) for access to the quarries, their hospitality and support of the fieldwork. We especially thank Yiannis Karpontinis for his help with this project, and many discussions about the Naxos Crystallina marble. B. Grasemann and G. Zulauf provided helpful and constructive comments on the manuscript. Ian Alsop is thanked for editorial handling.

\section{References}

Abe, S., Urai, J.L., 2012. Discrete element modeling of boudinage: insights on rock rheology, matrix flow, and evolution of geometry. Journal of Geophysical Research: Solid Earth (1978-2012) 117.

Abe, S., Urai, J.L., Kettermann, M., 2013. Fracture patterns in nonplane strain boudinage-insights from 3-D discrete element models. Journal of Geophysical Research: Solid Earth 118, 1304-1315.

Abe, S., van Gent, H.W., Urai, J., 2010. Discrete Element Modeling of Boudinage, in: Dietl, C., Zulauf, G., Dörr, W., Petscick, R. (Eds.), TSK13, Frankfurt am Main, Germany, p. 1.

Adamuszek, M., Schmid, D.W., Dabrowski, M., 2013. Theoretical analysis of large amplitude folding of a single viscous layer. J Struct Geol 48, 137-152.

Bai, T., Pollard, D.D., 2000. Spacing of fractures in a multilayer at fracture saturation. International Journal of Fracture 100, 23-28. 
Bons, P.D., Druguet, E., Hamann, I., Carreras, J., Passchier, C.W., 2004. Apparent boudinage in dykes. J Struct Geol 26, 625-636.

Dabrowski, M., Grasemann, B., 2014. Domino boudinage under layer-parallel simple shear. J Struct Geol 68, 5865.

Gardner, R.L., Piazolo, S., Daczko, N.R., 2015. Pinch and swell structures: evidence for strain localisation by brittle-viscous behaviour in the middle crust. Solid Earth 6, 1045-1061.

Gautier, P., Brun, J.P., Jolivet, L., 1993. Structure and kinematics of upper Cenozoic extensional detachment on Naxos and Paros (Cyclades Islands, Greece). Tectonics 12, 1180-1194.

Ghassemi, M.R., Schmalholz, S.M., Ghassemi, A.R., 2010. Kinematics of constant arc length folding for different fold shapes. J Struct Geol 32, 755-765.

Ghosh, S., 1988. Theory of chocolate tablet boudinage. J Struct Geol 10, 541-553.

Goldstein, A.G., 1988. Factors affecting the kinematic interpretation of asymmetric boudinage in shear zones. J Struct Geol 10, 707-715.

Goscombe, B.D., Passchier, C.W., 2003. Asymmetric boudins as shear sense indicators-an assessment from field data. J Struct Geol 25, 575-589.

Goscombe, B.D., Passchier, C.W., Hand, M., 2004. Boudinage classification: end-member boudin types and modified boudin structures. J Struct Geol 26, 739-763.

Grasemann, B., Schmalholz, S.M., 2012. Lateral fold growth and fold linkage. Geology 40, 1039-1042.

Grasemann, B., Stüwe, K., 2001. The development of flanking folds during simple shear and their use as kinematic indicators. J Struct Geol 23, 715-724.

Gueguen, E., Doglioni, C., Fernandez, M., 1997. Lithospheric boudinage in the Western Mediterranean back-arc basin. Terra Nova 9, 184-187.

Hanmer, S., 1986. Asymmetrical pull-aparts and foliation fish as kinematic indicators. J Struct Geol 8, 111-122.

Hudleston, P.J., Treagus, S.H., 2010. Information from folds: a review. J Struct Geol 32, 2042-2071.

Jolivet, L., Faccenna, C., Piromallo, C., 2009. From mantle to crust: stretching the Mediterranean. Earth Planet Sc Lett 285, 198-209.

Kaus, B.J., Schmalholz, S.M., 2006. 3D finite amplitude folding: implications for stress evolution during crustal and lithospheric deformation. Geophysical Research Letters 33.

Kenis, I., Urai, J., Van Der Zee, W., Sintubin, M., 2004. Mullions in the High-Ardenne Slate Belt (Belgium): numerical model and parameter sensitivity analysis. J Struct Geol 26, 1677-1692.

Kenis, I., Urai, J.L., van der Zee, W., Hilgers, C., Sintubin, M., 2005. Rheology of fine-grained siliciclastic rocks in the middle crust-evidence from structural and numerical analysis. Earth Planet Sc Lett 233, 351-360.

Kobberger, G., Zulauf, G., 1995. Experimental folding and boudinage under pure constrictional conditions. J Struct Geol 17, 1055-1063.

Komoróczi, A., Abe, S., Urai, J.L., 2013. Meshless numerical modeling of brittle-viscous deformation: first results on boudinage and hydrofracturing using a coupling of discrete element method (DEM) and smoothed particle hydrodynamics (SPH). Comput Geosci 17, 373-390.

Llorens, M.-G., Bons, P.D., Griera, A., Gomez-Rivas, E., Evans, L.A., 2013. Single layer folding in simple shear. J Struct Geol 50, 209-220.

Maeder, X., Passchier, C.W., Koehn, D., 2009. Modelling of segment structures: boudins, bone-boudins, mullions and related single-and multiphase deformation features. J Struct Geol 31, 817-830.

Passchier, C., 2001. Flanking structures. J Struct Geol 23, 951-962.

Ramberg, H., 1955. Natural and experimental boudinage and pinch-and-swell structures. The Journal of Geology, 512-526.

Reber, J., Schmalholz, S.M., Burg, J.-P., 2010. Stress orientation and fracturing during three-dimensional buckling: Numerical simulation and application to chocolate-tablet structures in folded turbidites, SW Portugal. Tectonophysics 493, 187-195.

Reuning, L., Schoenherr, J., Heimann, A., Urai, J.L., Littke, R., Kukla, P.A., Rawahi, Z., 2009. Constraints on the diagenesis, stratigraphy and internal dynamics of the surface-piercing salt domes in the Ghaba salt basin (Oman): a comparison to the Ara formation in the South Oman salt basin. GeoArabia 14, 83-120.

Ruh, J.B., Kaus, B.J.P., Burg, J.-P., 2012. Numerical investigation of deformation mechanics in fold-and-thrust belts: Influence of rheology of single and multiple décollements. Tectonics 31, TC3005. 
Schenk, O., Urai, J.L., van der Zee, W., 2007. Evolution of boudins under progressively decreasing pore pressureA case study of pegmatites enclosed in marble deforming at high grade metamorphic conditions, Naxos, Greece. Am J Sci 307, 1009-1033.

Schmalholz, S.M., Maeder, X., 2012. Pinch-and-swell structure and shear zones in viscoplastic layers. J Struct Geol $37,75-88$.

Schmalholz, S.M., Podladchikov, Y., 1999. Buckling versus folding: importance of viscoelasticity. Geophysical Research Letters 26, 2641-2644.

Schmalholz, S.M., Schmid, D.W., 2012. Folding in power-law viscous multi-layers. Philosophical Transactions of the Royal Society A: Mathematical, Physical and Engineering Sciences 370, 1798-1826.

Schmalholz, S.M., Schmid, D.W., Fletcher, R.C., 2008. Evolution of pinch-and-swell structures in a power-law layer. J Struct Geol 30, 649-663.

Schmid, D., Podladchikov, Y.Y., 2006. Fold amplification rates and dominant wavelength selection in multilayer stacks. Philosophical Magazine 86, 3409-3423.

Schoenherr, J., Reuning, L., Kukla, P.A., Littke, R., Urai, J.L., Siemann, M., Rawahi, Z., 2009. Halite cementation and carbonate diagenesis of intra-salt reservoirs from the Late Neoproterozoic to Early Cambrian Ara Group (South Oman Salt Basin). Sedimentology 56, 567-589.

Schöpfer, M.P., Arslan, A., Walsh, J.J., Childs, C., 2011. Reconciliation of contrasting theories for fracture spacing in layered rocks. J Struct Geol 33, 551-565.

Schöpfer, M.P., Childs, C., Manzocchi, T., Walsh, J.J., Nicol, A., Grasemann, B., 2017. The emergence of asymmetric normal fault systems under symmetric boundary conditions. J Struct Geol 104, 159-171.

Schrank, C.E., Boutelier, D.A., Cruden, A.R., 2008. The analogue shear zone: From rheology to associated geometry. J Struct Geol 30, 177-193.

Strozyk, F., Urai, J.L., van Gent, H., de Keijzer, M., Kukla, P.A., 2014. Regional variations in the structure of the Permian Zechstein 3 intrasalt stringer in the northern Netherlands: 3D seismic interpretation and implications for salt tectonic evolution. Interpretation 2, SM101-SM117.

Urai, J., Schuiling, R., Jansen, J., 1990. Alpine deformation on Naxos (Greece). Geological Society, London, Special Publications 54, 509-522.

Van Noten, K., Sintubin, M., 2010. Linear to non-linear relationship between vein spacing and layer thickness in centimetre-to decimetre-scale siliciclastic multilayers from the High-Ardenne slate belt (Belgium, Germany). J Struct Geol 32, 377-391.

Virgo, S., Abe, S., Urai, J.L., 2013. Extension fracture propagation in rocks with veins: Insight into the crack-seal process using Discrete Element Method modeling. Journal of Geophysical Research: Solid Earth 118, 2013JB010540.

Virgo, S., Abe, S., Urai, J.L., 2014. The evolution of crack-seal vein and fracture networks in an evolving stress field: insights from Discrete Element Models of fracture sealing. Journal of Geophysical Research 119, 87088727.

Virgo, S., von Hagke, C., Urai, J.L., 2018. Multiphase Boudinage: a case study of Amphibolites in Marble in the Naxos Migmatite core. Solid Earth 9, 1-23.

Weiss, L.E., 1972. The minor structures of deformed rocks: a photographic atlas. Springer-Verlag New York.

Wibberley, C.A., Petit, J.-P., Rives, T., 1999. Mechanics of high displacement gradient faulting prior to lithification. J Struct Geol 21, 251-257.

Zulauf, G., Zulauf, J., Bornemann, O., Kihm, N., Peinl, M., Zanella, F., 2009. Experimental deformation of a singlelayer anhydrite in halite matrix under bulk constriction. Part 1: Geometric and kinematic aspects. J Struct Geol 31, 460-474.

Zulauf, G., Zulauf, J., Hastreiter, P., Tomandl, B., 2003. A deformation apparatus for three-dimensional coaxial deformation and its application to rheologically stratified analogue material. J Struct Geol 25, 469-480.

Zulauf, J., Zulauf, G., 2005. Coeval folding and boudinage in four dimensions. J Struct Geol 27, 1061-1068.

Zulauf, J., Zulauf, G., Göttlich, J., Peinl, M., 2014. Formation of chocolate-tablet boudins: Results from scaled analogue models. J Struct Geol 68, 97-111.

Zulauf, J., Zulauf, G., Kraus, R., Gutiérrez-Alonso, G., Zanella, F., 2011. The origin of tablet boudinage: Results from experiments using power-law rock analogs. Tectonophysics 510, 327-336. 